Istanbul Finance Congress, November 1-2, 2018, Istanbul, Turkey.

\title{
THE ROLE AND IMPORTANCE OF EXPORT CREDIT INSURANCE IN SUPPORT OF EXPORT DEVELOPMENT AND ECONOMIC GROWTH
}

\author{
DOI: 10.17261/Pressacademia.2018.983 \\ PAP-IFC- V.8-2018(15)-p.66-70
}

\section{Muge Cetiner ${ }^{1}$, Selda Eke ${ }^{2}$}

${ }^{1}$ Istanbul Kultur University, Basin Express Campus, Istanbul, Turkey. m.cetiner@iku.edu.tr, ORCID: 0000-0003-1248-5335

${ }^{2}$ Istanbul Kultur University, Basin Express Campus, Istanbul, Turkey. seldaeke@yahoo.com, ORCID: 0000-0003-4162-3549

\section{To cite this document}

Cetiner, M., Eke, S. (2018). The role and importance of export credit insurance in support of export development and economic growth. PressAcademia Procedia (PAP), V.8, p.66-70.

Permemant link to this document: http://doi.org/10.17261/Pressacademia.2018.983

Copyright: Published by PressAcademia and limited licenced re-use rights only.

\section{ABSTRACT}

Purpose- The purpose of this study is to evaluate the effectiveness of the insured trade credit on the international trade abroad and in our country and to raise awareness about the issue that has great potential for growth in our country in the future.

Methodolgy- The studies investigating the effect of the insured open account trade by private and officially supported export credit agencies on the development of exports and in general international trade were examined. In the second stage, the effect of export growth on economic development have been investigated in order to assess the impact of insured exports on economic growth. The fundamental concepts with the literature review have been investigated.

Findings- Through the literature review, the following facts have been obtained. Supplier credit leads to the increase in sales of the supplier and that in turn leads to company growth. It is also an important financing source for the buyer who buys and sells on credit and that leads to an increase in trade flows. It is complementary and alternative to bank loans especially in the periods of financial constraints when the companies need working capital finance. Insured open account trade leads to an increase in exports of the country. At macro level, there is a dual causality relationship between export growth and economic development.

Conclusion- As the result of the study, it has been concluded that the insured trade credit promotes the growth of trade flows and supply chains that lead to the growth in trade volumes and economic growth.

Keywords: Supplier credit, open account trade, export credit insurance.

JEL Codes: G22, B17, F13

\section{IHRACATIN DESTEKLENMESINDE İHRACAT KREDI SIGORTASININ ROL VE ÖNEMI, EKONOMIK BÜYÜMEYE KATKISI}

\section{ÖZET}

Amaç- Bu çalışmada amaçlanan gerek ülkemizde gerekse yurtdışında sigortalanmış kredili ticaretin dış ticaret üzerindeki etkisinin araştırılması ve konunun önemi üzerinde farkındalık yaratarak ülkemizde gelecekte çok büyüyebilecek bir potansiyele dikkat çekmektir.

Yöntem- Resmi destekli ihracat kredi sigortası ya da özel sektör kredi sigortası kuruluşları tarafından sigortalanan açık hesap ticaretin, ihracatın ve genel olarak uluslararası ticaretin gelişimine olan desteği konusunda yapılan çalışma örnekleri incelenmiştir. İhracatın ekonomik büyüme üzerindeki etkisi üzerinde durularak, ihracat kredi sigortası desteği irdelenmiştir. Temel kavramlar ve literatür çalışmaları özetlenmiştir.

Bulgular- Literatür taraması sonucunda elde edilen bulgular şunlardır: Tedarikçi kredisi, tedarikçi firmaların satışlarını arttırarak firma büyümesine katkı sağlamaktadır. Alııı firmalar için de önemli bir finansman kaynağı olmaktadır. Alııı şirketin kendisi de müşterilerine kredili satış yapabildiğinden, ticari akımlarda artış sağlanmaktadır. Tedarikçi kredisi işletme sermayesi ihtiyacının karşılanmasında banka kredilerine yönelen şirket için finansman ihtiyacını tamamlayan bir rol oynamakta ve özellikle finansal sıkışıkıkların olduğu dönemlerde, banka kredisine alternatif bir finansman kaynağı olmaktadır. Açık hesap ticaretin sigortalanması, ülkenin ihracatını arttırma konusunda son derece önemli bir role sahiptir. Makro düzeyde, ihracatın büyümesi ile ekonomik gelişme arasında da iki yönlü bir nedensellik ilişkisi bulunmaktadır.

Sonuç- Çalışmada sigortalanmış kredili satışların ticari akımları destekleyecekleri, tedarik zincirlerinin büyümesine neden olmaları sonucunda da, ticaret hacminin artmasına, ekonomik büyümeye katkı sağlayacakları sonucuna ulaşıımışıır.

Anahtar Kelimeler: Tedarikçi kredisi, açık hesap ticaret, ihracat kredi sigortası.

JEL Kodları: G22, B17, F13 


\section{GiRiş}

Dünya ticaretinin gelişiminde sınırötesi ticaret önemli bir rol oynar. Sınırötesi ticarette şirketler makro düzeydeki risklerin yanısıra, mal bedelinin tahsil edilememesi sonucunu doğuran ticari ve politik risklerle karşılaşırlar. Şirketlerin faaliyetlerini sürdürülebilmeleri için bu risklerin olumsuz etkilerine karşı kendilerini korumaları gerekmektedir. Şirketler ticaret finansmanı araçları ile çeşitli sigorta ve garanti yöntemlerinden yararlanarak emniyetli bir şekilde kredili satıs yapma imkanı elde etmektedirler. Ticaret finansmanı, tanımı itibarıyla bankalar tarafından sunulan ticaret finansmanı araçları ile şirketlerarası kredili ticari faaliyetler (tedarikçi kredisi) ve bu faaliyetlerin sürdürülmesine yönelik banka dışındaki kuruluşların sunduğu kredi sigortası ve diğer garanti ve finansman araçlarından oluşur. Dünya ticaretinin \% 80-90'ından fazlasının ticaret finansmanı araçları ile yürütüldüğü kabul edilmektedir. (Auboin, 2009) ) Bu nedenle, finansal friksiyonların olduğu dönemlerde, ticaret finansmanı pazarında kapasitenin azaldığı ve kredi piyasalarında daralmaların gözlemlendiği dönemlerde ihracatta ve uluslararası ticarette daralma görülmektedir. (Chor \& Manova, 2012) Amiti ve Weinstein'a göre,ihracat faaliyetlerinin bu friksiyonların olumsuz etkilerinden daha çok etkilenmesinin sebebi ihracatta karşılaşılan ticari riskin yüksek olması nedeniyle ihracatın ticaret finansmanı araçlarına daha bağımlı olması ve dünyada ihracatın büyük bir oranda açık hesap ticarete yönelmiş olmasıdır. (Amiti \& Weinstein, 2009)Global pazarlara erişmek isteyen ve faaliyetlerini büyütmek isteyen firmalar açık hesap ticarete yönelmişlerdir. Özel sektör kuruluşları ve resmi destekli ihracat kredi sigortası kuruluşları tarafından sunulan ticari alacak sigortası olarak da bilinen ihracat kredi sigortası ile ihracatçı firmalar kendilerini açık hesap satışlarından dolayı maruz kalabilecekleri ticari ve politik risklere karşı güvence altına almaktadırlar. Kredi sigortası pazarında faaliyet gösteren özel sektör kuruluşlarının faaliyetleri genellikle kısa vadeli kredi riskinin teminat alınmasına yönelik sigorta faaliyetlerini kapsar. Resmi destekli ihracat kredi sigortası kuruluşlarının faaliyetleri ise (Export Credit Agency- ECA'ler) ülke hükümetleri adına ülke ihracatını desteklemektir. Bu amaçla, ihracat kredi sigortası desteği ile doğrudan kredilendirme faaliyetlerinde bulunurlar.Aynı zamanda sınır ötesi yatırım risklerine ilişkin çeşitli sigorta poliçeleri düzenlerler. (Çetiner \& Eke, 2018) ìhracat kredi sigortası programları, Dünya Ticaret Örgütünün (DTÖ) resmi kuruluşlar tarafından ihracata verilen garanti desteğine ilişkin sınırlamalarıyla , OECD Mutabakatı ile belirlenmiş kurallara ve Avrupa Birliğinin norm ve kurallarına uygun olarak yürütülmektedir.ihracatın hükümetler tarafından desteklenmesinin ülkelerarası rekabeti engelleyeceği ve çok taraflı ticaret sistemini bozacağı kaygısı ile DTÖ hükümetlerin bu desteğini belirli dönemler haricinde kısıtlamaktadır. Finansal friksiyonların olduğu dönemlerde, özel sektör kuruluşlarının sigortalama faaliyetlerini azalttığı dönemlerde resmi destekli kuruluşların bu açığı telafi etmek üzere ticaret finansmanı pazarına girmesi konusunda bir istisna tanınmıştır. (Ferbermayr \& Yalçın, 2013) 2008-2009 finansal krizi döneminde de görüldüğü üzere resmi ihracat kredi sigortası kuruluşları, bu açığı kapatmak için ticaret finansmanı pazarında aktif bir rol oynamışlardır. (Chaffeaur \& Malouche, 2011) Bu makalede, literatür çalışmalarından yararlanılarak ihracat kredi sigortası kuruluşlarının sigorta faaliyetlerinin ihracatın arttıııması konusunda ne ölçüde etkin olduğu ve böylelikle ekonomik büyümeye katkısının ne olacağına ilişkin bir sonuca varılmaya çalışılmaktadır.

\subsection{Ihracatın Ekonomik Büyüme Üzerindeki Etkisi}

Gelişmekte olan ülkelerde ihracattaki artışın ekonomik büyümeyi artıracağı beklentisi, korumacı politikaların terk edilip, liberal politikaların tercih edilmesinde etkili olmaktadır.

Son dönemlerde, gerek gelişmiş ülkelerde gerekse gelişmekte olan ülkeler açısından ihracat ile büyüme arasında pozitif yönlü ve uzun dönemi kapsayan bir ilişki olduğuna yönelik olarak yapılmış pek çok akademik araştırma bulunmaktadır. Yurtiçinde ve yurtdışında yapılan bazı çalışma örneklerine aşağıda yer verilmiştir.

12 ülke verileri kullanılarak ekonomik büyümenin nedenleri üzerinde yoğunlaşılan bir araştırmada, ihracatla birlikte ülkeye döviz girişi sağlandığı için üretim kapasitesi artmakta, verimli ve uzmanlaşmış sektörlerde performans daha üst düzeyde olduğu için ekonomik büyüme gerçekleşmektedir bulgusuna ulaşılmıştır. (Ağayev, 2011). İhracatın, gelişmiş ülkeler ve yüksek teknolojik ürünler üreten ülkelerde büyümeyi pozitif yönde etkilediği yönündeki bulgulara (Kugler, 1991), (Parikh \& Stirbu, 2004) çalışmalarında rastlanmıştır.Asya ülkelerinde gerçekleştirilen çalışmalarda ; reel gayri safi yurtiçi hasıla ve ihracat artış hızı verileri kullanılarak çeşitli araştırmacılar tarafından testler gerçekleştirilmiştir. (P.C.Y., 1987), (A.F., 1987), (J.K., 1991), (J.C., 1995), (M.N., 1998), (E.M., 1999). Bulgular kısa dönem analizlerinde ihracata dayalı büyümeyi destekleyici yönde olmuş ancak uzun dönemli ilişkilerde bir ilişki bulunamamıştır. Benzer şekilde Afrika ülkelerinde yapılan araştırmalarda ihracat artış hızıyla Gayri Safi Yurt İçi Hasıla verileri kullanılarak en küçük kareler yöntemiyle nedensellik testleri yapılmış ve elde edilen bulgulara göre ihracattaki artışın büyümeyi desteklediği ortaya çıkmıştır. (Shigeyoki \& Razafimahefu, 2003), (Fosu, 1990)BRIC ülkeleri veri seti olarak alınıp gerçekleştirilen bir başka çalışmada temel amaç, Brezilya, Rusya, Hindistan ve Çin'de ihracat ile ekonomik büyüme arasındaki ilişkiyi incelemektir. Analiz sonuçlarına göre, gerek kısa gerekse uzun vadedeki ilişki, ihracattan ekonomik büyümeye doğru olarak bulunmuş ve tam tersi bir durumun anlamlı bulunmadığı gösterilmiştir. Buradan yola çıkılarak, ihracata dayalı büyüme hipotezinin BRIC ülkelerinde geçerli olduğu şeklinde yorum yapılmıştır. (Sandalcılar, 2012)Bir başka çalışmada ekonomik büyüme ölçütü, sanayi üretim endeksi alınmış ve ihracatla olan nedensellik ilişkisi araştırılmıştır. Sonuçta, ihracattan büyümeye doğru tek taraflı bir nedensellik ilişkisinin varlığı tespit edilmiştir. (Özmen, Özer, \& Türkyılmaz, 1999)1980 - 1996 döneminde ihracat ve büyüme değişkenlerinin logaritmik farklarını hesaplayarak gerçekleştirdikleri çalışmalarında büyümeden ihracata yönelik olarak doğru tek yönlü nedensellik ilişkisi gözlemlemişlerdir. (Yiğidim \& Köse, 1997)Başka bir çalışmada ülkemizde 1996-2006 dönemindeki ihracat, ithalat ve ekonomik büyüme ilişkilere bakılmış ve ihracat, ithalat ve ekonomik büyüme arasında uzun vadede bir denge ilişkisi varlığı görülmüştür.Analizler sonucunda kısa dönemde ithalat, ihracat ve ekonomik büyüme arasında iki yönlü olan bir nedensellik ilişkisi tespit edilmiş ve uzun dönemde, ihracattan ithalata, ithalattan ihracata, büyümeden ihracata ve büyümeden ithalata yönelik olarak tek yönlü bir nedensellik ilişkisinin varlığı gösterilmiştir. (Aktaş, 2009)1989-2011 dönemini kapsayan bir başka çalişmada, ihracat ve ithalatın ekonomik büyüme üzerindeki etkileri üzerinde çalışılmış ve ekonominin gerek büyüme gerekse küçülme gösterdiği her iki dönemde de hem ihracat hem de ithalatın ekonomik büyümeyi olumlu yönde etkilediği gözlemlenmiştir. Bu sonuç ihracata yönelik olan bir sanayileşme modelinin sağlıklı bir model olduğunun da ispatı olmaktadır. (Saraç, 2013)Amacı, 1987-2007 dönemindeki aylık verilerle ülkemizde ihracat ile büyüme arasındaki ilişkileri ya da ihracata dayalı büyüme hipotezini test etmek olan bir diğer çalışmada ihracat, ithalat, dış ticaret hadleri ve sanayi üretim endeksi değişkenleri arasındaki uzun vadeli ilişkiler değerlendirilmiştir. Sonuçlarda ihracata dayalı büyüme modeli ile bağlantılı şekilde, ihracattan sanayi üretim endeksine doğru tek yönlü bir nedensellik ilişkisine ek olarak, ihracat ile dış ticaret hadleri arasında çift yönlü nedensellik 
ilişkisi elde edilmiştir. (Bilgin \& Şahbaz, 2009)Başka bir çalışmada, ülkemizde 2005-2011 döneminde ihracat, ithalat, sanayi üretim endeksi ve reel döviz kuru arasındaki karşılıklı ilişkileri dikkate alınmış ve ihracata dayalı büyüme modelini doğrular nitelikte olarak Türkiye'nin ihracatındaki büyümenin ekonomisini de büyümesine olumlu yönde etki eden bir araç olduğu görülmüştür. (Özcan \& Özçelebi, 2013)Ülkemizde 2002 yılından itibaren büyüme ihracata dayalı hale geldiğinden gerek ihracat gerekse ekonomik büyüme değişkenlerinin kullanılarak aralarında nedensellik ilişsilerinin araştırıldığı çok sayıda çalışmadan bir diğeri olan Korkmaz'ın çalışmasında, ihracattan büyümeye doğru tek yönlü nedensellik saptanarak, ülke ekonomisinin büyümesi ve iktisadi kalkınmada ihracatın pozitif etkisi gösterilmiş ve ihracatı arttıran ürünlerin ithal hammaddelerle sağlanması durumunda oluşabilecek cari açık tehlikesine dikkat çekilmiştir. (Korkmaz, 2014)Dış ticaret ile ekonomik büyüme arasındaki ilişki gelişmiş ve gelişmekte olan ülkelerde araştırıldığında Türkiye'nin de aralarında bulunduğu 7 gelişmekte olan ülke ile 12 gelişmiş ülke için dış ticaret ile büyüme ilişkisinin irdelendiği bir diğer çalışmada, büyümeden ithalata ve ihracata doğru bir nedensellik ilişkisi bulunamamakla birlikte, hem gelişmiş hem de gelişmekte olan ülkelerde, ithalat ve ihracattan büyümeye doğru bir nedensellik ilişkisinin varlığına rastlanmıştır. (Gül \& Kamacı, 2012)

\section{2. İhracat Kredi Sigortasının İhracatı Arttırmak Konusundaki Rol ve Önemi}

Uluslararası ticaretin gelişmesinde, ülke ihracatının arttırılmasında kredi sigortasının rol ve öneminin anlaşılması amacıyla iki aşamalı bir literatür çalışması yapılmıştır. Kredi sigortası tedarikçinin kredili satışlarını teminat altına alan bir risk yönetim aracıdır. Bu nedenle, öncelikle şirketlerarası kredili satışların ticaretin büyümesine sağladığı katkının analiz edildiği çalışmalara başvurulmuştur. Şayet kredili ticaret, şirket satışlarını her iki yönde de ; hem ana tedarikçinin satışlarını arttırma, hem de alıcının da kendi müşterilerine kredili satış yapmasına imkan vererek alıcının da bir tedarikçi olarak satışlarını arttırması yönünde bir katkı sağlıyorsa o halde şirketlerarası kredili ticaretin sürdürülmesi gereklidir. Tedarikçi kredisi, satıcının alıcıya mal alımı sırasında peşin ödeme yapmak yerine vadeli ödeme yapması için tanıdığı belirli bir süre nedeniyle oluşur. Tedarikçi, bankanın alıcıya sağladığı işletme sermayesi finansmanının yerine geçebilecek şekilde alıcıya bir finansman imkanı sağlamaktadır. Tedarikçi kredili satış yaparak satışlarını büyütürken alıcı ise ödemesini peşin yapmadığı için bir finansman imkanı elde etmektedir. Bu finansman imkanından yararlanan alıcının kendisi de tedarik zinciri içerisinde kendi müşterisine kredili satış yapma imkanı elde eder. Böylece zincir giderek büyür. Bu zincirin büyümesi ise ticaretin artmasını sağlar. Fernando ve Mulier'in yaptıkları çalışmanın sonucuna göre tedarikçiden sağlanan bu kredi imkanı firmaların satışlarını arttırarak ticarette büyümeyi sağlamaktadır. (Ferrando \& Mulier, 2013)Tedarikçinin sağladığı bu finansman imkanının bankadan temin edilen kredilere alternatif oluşturup oluşturmadığı veya hangi durumlarda banka kredisini ikame edebildiği konularında yapılan çalışmaları da bu kapsamda değerlendirmek mümkündür. Şayet tedarikçi kredisi banka kredilerine ulaşılmasının zor olduğu dönemlerde alıcı için bir finansman alternatifi oluşturuyorsa, o halde ticaretin sürdürülebilirliği için son derece önemli bir finansma imkanı sağlanmaktadır. Yapıla ampirik çalışmaların sonuçlarına göre, özellikle finansal kriz dönemlerinde banka kredilerine ulaşılmasının zor olduğu dönemlerde şirketler ticaretlerini sürdürülebilmek amacıyla tedarikçi kredisinden daha fazla yararlanmaktadırlar. (Fisman \& Love , 2003) Gerek Nisen, gerekse Petersen de benzer türde çalışmalar yapmıştır. Tedarikçinin sağladığı bu kredili satış imkanı giderek artan oranda açık hesaba dayalı ticarete yönelmektedir. Bu ticarette tedarikçinin taşıdığı risk çok yüksektir. Açık hesap ticarette, tedarikçi lehine banka tarafından düzenlenen herhangi bir ödeme garantisi ya da lehine alıcının bankası tarafından açılan bir akreditif yoktur. (Petersen \& Raghuran, 1997)Tedarikçi malların yüklenmesiyle birlikte faturasını düzenler. Fatura vadesinde alıcının doğrudan satıcıya ödemesini yapması beklenir. Bu bağlamda kredi sigortasının ticaretin sürdürülebilirliğine yaptığı katkı, tedarikçinin kredili ve açık hesap ihracatını ticari ve politik risklere karşı güvence altına alması nedeniyle ortaya çıkmaktadır. (Nilsen, 1999)

Kredi sigortasının doğrudan ihracat üzerindeki etkisinin analiz edildiği çalışmalar da mevcuttur.Bu çalışmalarda farklı ülkelere yönelik olarak ampirik verilerle çalışmalar ve saha çalışmaları yapılmıştır. Bu araştırmaların çoğunlukla ülkelerin resmi destekli ihracat kredi sigortası kuruluşları için yapıldığı görülmektedir. Çeşitli tarihlerde yapılan bu çalışmaların bir çoğunda sigorta ve garanti desteğinin ihracatı arttırmak konusunda olumlu bir etkiye sahip olduğu sonucuna varılmıştır. Bu çalışmalardan bazıları aşağıda verilmektedir:

Egger ve Url, Avusturya ihracat kredi sigortası kuruluşu Kontrollbank (OeKB) tarafından sağlanan ihracat garantilerinin ihracat üzerindeki etkisini incelemişlerdir. Bu çalışmanın sonucuna göre sigortanın etkisi ile ihracat \% 100 - \% 130 oranları arasında artmaktadır. (Egger \& Url, 2010) Moser, Nestmann ve Wedow, Almanya'da Euler Hermes'in Alman hükümeti adına verdiği ihracat kredi sigortası desteğinin etkisini ölçebilmek amacıyla bir çalışma yürütmüşlerdir. Bu çalışmanın sonucuna göre, sigortanın ihracatı arttırmak konusunda etkin olduğu ve ihracatı 1.7 oranında arttırdığı hesaplanmıştır. (Moser, Nestmann , \& Wedow, 2008). Aynı ülke ve kuruluş için benzer bir çalışma Felbelmayr ve Yalçın tarafından 2010 yılında yapılmıştır. Bu çalışmanın sonucuna göre verilen garantilerde \% 1'lik artış ihracatı \% 0.012 ile $0.017 \%$ oranında arttırmaktadır. Çalışmada bazı sektörlerin sigorta desteğinden daha fazla yararlandığı tespit edilmiştir. Aynı şekilde, bazı ürünlerin ihracatı daha fazla artmaktadır. Özellikle 2008 finansal krizinde bu olumlu etkinin daha yüksek olduğu gözlemlenmektedir. (Felbermayr \& Yalçın, 2010) Alvarez ve Crespi, Şili için yaptıkları çalışmada ihracatta sigorta ve garanti desteğinin önemini analiz etmişlerdir. İhracatı arttırmaya yönelik uygulamalar teknolojik yenilikleri desteklemekte, yeni ürünlerin piyasaya sunulması yönünde fayda sağlamakta ve organizasyonel anlamda yenilik getirmektedir. Bu etkinin ihracata olan etkisi rakamsal olarak da ölçülmüştür. Yeni ürünlerle yeni pazarlara ulaşma konusunda ihracat garanti desteğinin önemli olduğu sonucuna varılmıştır. (Alvarez E. \& Gustavo, 2000)) Van der Veer, özel sektör kuruluşlarının düzenlediği ihracat kredi sigortasının ticaret hacmi üzerindeki etkisini göstermek amacıyla bir çalışma yapmıştır. Özel sektör kuruluşları için yapılan çalışmalar çok az sayıdadır. Bu çalışmada özel sektör pazarındaki üç büyük şirketin (Euler Hermes, Atradius, Coface) verilerinden yararlanılmıştır. Çalışmanın sonucuna göre, sigortalanmış açık hesap ihracat uluslararası ticaret hacmi üzerinde bir çarpan etkisi yaratmaktadır. Sigortalanmış her 1 Euro'luk ihracat, toplam ihracat üzerinde 1,3 Euro'luk bir etki oluşturmaktadır. Bunun sebeplerinden biri şirketlerin daha önce riskli gördükleri için ihracat yapamadıkları ülkelere kredi sigortası ile ihracat yapabilme imkanı elde etmeleridir. Diğeri ithalatın açık hesap şeklinde yapılabilmesinin ithalat talebini olumlu yönde desteklemesidir. (Van Der Veer, 2005)Auboin ve Engemann, Berne Union verilerinden yararlanarak 2005-2011 yıllarını kapsayacak bir analiz yapmışlardır. Çalışmanın sonucuna göre sigortalanmış açık hesap ticaret, global ticaret hacmi üzerinde oldukça yüksek bir etkiye sahiptir. 2008-2009 finansal kriz dönemi dahil, kriz dönemi öncesi ya da sonrası sigortanın ihracat üzerindeki etkisi olumlu yöndedir. Bir ülkeye yapılan kredili ve açık hesap ticaretteki \% 1 'lik artış, satış yapılan o ülkenin reel ithalatında \% 0.4'lük bir artışa sebep olmaktadır. (Auboin, 2009) Polat ve Yeşilyaprak, 2000-2015 yıllarını kapsayan çalışmalarında, Türk Eximbank 'ın Türkiye ihracatı üzerindeki etkisini ampirik verilerle ölçmeye çalışmışlardır. Çalışma sonucuna göre ihracat kredi sigortası desteği ihracatın artışını desteklemektedir. (Polat \& Yeşilyaprak, 2017) 


\section{SONUÇ}

Dünya ticareti büyük oranda açık hesap ticarete yönelmiştir. Kredi sigortası bu ticareti güvence altına alan bir risk yönetim aracı ve ticaret finansmanı enstrümanıdır. Ticaretin sürdürülebilirliği, tedarik zincirinde ticari akımların sürekliliğinin sağlanmasına bağlıdır . Kredili ticaret ile tedarikçiler mal ve hizmet satışlarını artıııılar. Tedarikçi kredisi alıcı için bir finansman imkanı yaratır. Özellikle finansal krizlerin olduğu dönemlerde tedarikçinin sağladığı bu kredi , banka kredisine alternatif bir finansman kaynağıdır. Alım yapan firmalar kendilerine tanınan bu kredili mal alım imkanında yararlanırlar ve kendileri de müşterilerine kredili satı̧ yapma imkanı elde ederler. Kredi sigortası, bu ticaretin güvenli bir şekilde sürdürülebilmesi için tedarikçiye bir garanti imkanı sağlarken, alııı tedarikçi lehine vereceği bir banka garantisine ihtiyaç duymadan ve banka kredi limitlerini kullanmadan açık hesap bazında mal temin edebilmektedir. Yapılan çalışmalarda tedarikçi kredisinin firma büyümesine etkisi araştırımıştır. Tedarikçi kredisinin banka kredisine alternatif oluşturup oluşturmadığı veya hangi durumlarda daha etkin olduğuna yönelik çalışmalar yapılmışır. Kredi sigortasının doğrudan ihracat üzerindeki etkisinin analiz edildiği ampirik verilerin kullanıldığı yapılan çalışmalar ile saha çalışmaları da mevcuttur. Bu araştırmaların çoğunlukla ülkelerin resmi destekli ihracat kredi sigortası kuruluşlarının ihracat garanti desteğini ölçme amaçlı yapıldığı görülmektedir. Bununla birlikte özel sektör kuruluşlarının da ticaretin gelişimi üzerindeki etkisinin analiz edildiği çalışmalar da mevcuttur. Bu çalışmaların bazıları özellikle 2008-2009 finansal krizinin dünya ticareti üzerindeki olumsuz etkileri düşünülerek bu dönemi kapsayacak şekilde yapılmışır. Çeşitli tarihlerde yapılan bu çalışmalarda finansal kriz dönemi de dahil olmak üzere sigorta ve garanti desteğinin ihracatı arttırmak konusunda olumlu bir etkiye sahip olduğu sonucuna varıımıştır. Özel ve resmi destekli kredi sigortası kuruluşlarının derneği olan Berne Union 'ın açıkladığı 2017 verilerine göre dünya mal ve hizmet ticaretinin \% 13 'ü bu kuruluşlar tarafından güvence altına alınmaktadır. Bu ticaretin yaklaşık \% 90'u kısa vadeli ihracat kredi sigortası ile teminat altına alınmaktadır. Bu ticaretin yaklaşık \% 60'ı ise özel sektör kuruluşları tarafından sigortalanmaktadır. Bu kuruluşların dünya ticaretinin gelişiminde önemli bir rol oynadığı görülmektedir. Dünya ticaretinin büyümesi ile ekonomik büyüme arasındaki ilişkinin araştırıldı̆̆ı çeşitli araştırmalarda ise gerek teorik açıklamalar gerekse ampirik çalışmalar bu ilişkinin ihracat ile büyüme arasında pozitif yönlü ve uzun dönemi kapsayan bir ilişki olduğuna yöneliktir. Bu çalışmaların sonucuna göre ihracat kredi sigortası kuruluşlarının ihracatın büyümesine yönelik sağladığı bu katkı ekonomik büyümenin de sağlanmasına yönelik olmaktadır. Ülke ihracatını 2017 yılı itibarıyla yaklaşık \% 70 oranında açık hesap ödeme şekli ile yürütüldüğü düşünüldüğünde, ülkede faaliyet gösteren ihracat kredi sigortası kuruluşlarının bu ticaretin sürdürülebilirliğinde rol ve önemi dikkate alınmalıdır. Bu garanti desteğinin arttırılmasına yönelik çalışmalar ivedilikle ele alınmalıdır.

\section{KAYNAKÇA}

A.F., D. (1987). Are Exports an Engine of Growth? Another Look at the Evidence. Applied Economics, 19(2), $277-283$.

Ağayev, S. (2011). İhracat ve Ekonomik Büyüme İlişkisi:12 Geçiş Ekonomisi Örneğinde Panel Eşbütünleşme ve Panel Nedensellik Analizleri. Ege Akademik Bakış, 11(2), 241-254.

Aktaş, C. (2009). Türkiye'nin İhracat, İthalat Ve Ekonomik Büyüme Arasındaki Nedensellik Analizi. Kocaeli Üniversitesi Sosyal Bilimler Enstitüsü Dergisi, 18(2), 35-47.

Alvarez E., R., \& Gustavo, C. (2000). Exporter Performance and Promotion Instruments: Chielean Emprical Evidence. Estudios de Economia.

Amiti, M., \& Weinstein, D. (2009). Exports and Financial Shocks. NBER Working Paper Series. http://www.nber.org/papers/w15556 adresinden alındı

Auboin, M. (2009). Boosting the Availability of Trade Finance in the Current Crisis: background Analysis for a Substantial G20 Package. CEPR Policy Insight.

Bilgin, C., \& Şahbaz, A. (2009). Türkiye'de Büyüme ve İhracat Arasındaki Nedensellik i̇lişkileri. Gaziantep Üniversitesi Sosyal Bilimler Dergisi, 8(1), 177-198. 8http://sbe.gantep.edu.tr adresinden alındı

Chaffeaur, J., \& Malouche, M. (2011). Trade Finance During the Great Trade Collapse,The Wordbank. The World Bank, 337-341.

Chor, D., \& Manova, K. (2012). Off the Cliff and Back? Credit Conditions and International Trade During the Global Financial Crisis. Journal of International Ecominics, 117-133.

Çetiner, M., \& Eke, S. (2018). Güncel Gelişmeler Işığında Kredi Sigortası Pazarı Ve Makro Açıdan İrdelenmesi. Social Science Development Journal, 3(12), 496-507.

E.M., E. (1999). Exports and Economic Growth in Asian Developing Countries: Cointegration and Error Correction Models. Journal of Economic Development, 24(2), 43-56.

Egger, P., \& Url, T. (2010). The World Economy, 29(4), 399-418. doi:http:// doi.org/10.1111/j.1467-9701.2006,00790.x

Felbermayr, G. J., \& Yalçın, E. (2010). Export Credit Guarantees and Export Performance. World Economy, 36(8), 967-999. doi:http:// doi.org/10.1111/twec.12031

Ferbermayr, G. J., \& Yalçın, E. (2013). Export Credit Guarantees and Export Performance: An Empirical Analysis for Germany. The World Economy, 967-999. doi:10.1111/twec.12031 
Ferrando, A., \& Mulier, K. (2013). Do Firms Use the Trade Credit Channel to Manage Growth? Journal of Banking \& Finance(37), $3035-3046$.

Fisman, R., \& Love , I. (2003). Trade Credit, Financial Intermediary Development And Industry Growth. http://www.jstor.org/stable/3094490 adresinden alındı

Fosu, A. (1990). Exports and Economic Growth: The African Case. World Development, 18(6), 831-835.

Gül, E., \& Kamacı, A. (2012). Dış Ticaretin Büyüme Üzerine Etkileri: Bir Panel Veri Analizi. Uluslararası Alanya İşletme Fakültesi Dergisi, 4(3), 81-91.

J.C., J. (1995). Export-led Growth and the Four Little Dragons. International Trade and Economic Development, 4(2), $203-215$.

J.K., S. (1991). Rapid growth in NICs in Asia: Tests of New Growth Theory for Korea. Kyklos, 44(4), 561-579.

Korkmaz, S. (2014). Türkiye Ekonomisinde Đhracat ve Ekonomik Büyüme Arasındaki Nedensellik ilişkisi. Business and Economics Research Journal, 5(4), 119-128.

Kugler, P. (1991). Growth, Exports and Cointegration: An Empirical Investigation. Weltwirtschaftliches Archive, 127(2), 73-81.

M.N., I. (1998). Exports Expansion and Economic Growth: Testing for Cointegration and Causality. Applied Economics, 30(3), 415-425

(2017). Market Trends of Private Reinsurance in the Field of Export Credit Insurance. European Commision.

https://www.eximbank.gov.tr/tr/finansal-bilgiler/faaliyetraporlari adresinden alındı

Moser, C., Nestmann , T., \& Wedow, M. (2008). Political Risk and Export Promotion: Evidence from Germany.

Nilsen, J. (1999). Trade Credit\&the Bank Lending Channel Working Paper. Swiss National Bank.

Özcan, B., \& Özçelebi, O. (2013). İhracata Dayalı Büyüme Hipotezi Türkiye İçin Geçerli mi? Yönetim ve Ekonomi, 20 (1), 1-14.

Özmen, A., Özer, M., \& Türkyılmaz, S. (1999). Türkiye'de İhracat ve Ekonomik Büyüme Arasındaki Nedenselliğe İlişkin Bir Uygulama Denemesi. Marmara Üniversitesi Yayınları(640), 379-392.

P.C.Y., C. (1987). Causality Between Export Growth and Industrial Development. Journal of Development Economics, 26(1), 55-63. doi:https://doi.org/10.1016/0304-3878(87)90051-4

Parikh, A., \& Stirbu, C. (2004). Relationship Between Trade Liberalisation, Economic Growth and Trade Balance: An Econopmetric Investigation. http://www.hwwa.de/Publikationen/Discussion_paper/2004/282.pdf,(15/06/2005). adresinden alındı

Petersen, M. A., \& Raghuran, G. (1997). Trade Credit: Theories And Evidence The Review Of Financial Studies. http://www.jstore.org/stable/2962200 adresinden alındı

Polat, A., \& Yeşilyaprak, M. (2017). Export Credit Insurance And Export Performance: An Empirical Gravity Analysis For Turkey. International Journal Of Economics And Finance(12-24), 12-24

Sandalcılar, A. R. (2012). BRIC Ülkelerinde Ekonomik Büyüme ve İhracat Arasındaki ilişki: Panel Eşbütünleşme ve Panel Nedensellik. Süleyman Demirel Üniversitesi IiBF Dergisi, 17(1), 161-179.

Saraç, T. B. (2013). íhracat ve ithalatin Ekonomik Büyüme Üzeríndekí Etkísí: Türkiye Örnegi. Ege Akademik Bakış, 13(2), $181-194$.

Shigeyoki, H., \& Razafimahefu, I. (2003). Trade and Growth Relationship: Some Evidence From Comoros,Madagaskar, Mauritius and Seychelles. http://www.asafas.kyoto_u.ac.jp/asafbook/pdf/no_03/p174_185.pdf adresinden alındı

Van Der Veer, K. (2005). Journal Of Risk And Insurance. 601-624. doi:http://doi.org/10.1111/jori.12034

Yiğidim, A., \& Köse, N. (1997). İhracat ve Ekonomik Büyüme Arasındaki İlişki,İthaaltın Rolü:Türkiye Örneği (1980-1996). Ekonomik Yaklaşım(8), 71-85 